\title{
Serological response to Campylobacter jejuni/coli infection
}

\author{
DM JONES, JOAN ELDRIDGE, AND BAS DALE \\ From the Public Health Laboratory, Withington Hospital, Manchester M20 8LR, UK
}

SUMMARY The antibody response to Campylobacter jejuni/coli infection was investigated in 59 patients involved in two outbreaks of milk-borne infection and in sporadic infections in the community. Agglutinins and complement-fixing (CF) antibodies were detected in nearly all these patients. Agglutinins were present in $25 \%$ of normal sera at low titres (not greater than $1 / 160$ ) but CF antibody titres of $1 / 4$ or $1 / 8$ were present in only $2.0 \%$. The agglutination reactions in convalescent sera were best developed with the homologous or an antigenically similar strain whereas the CF test, with sonicated organisms as antigen, was less strain-specific and was more suitable as a routine test. Antibody was present seven to 10 days after the onset of symptoms.

Campylobacter jejuni/coli has become recognised as an important cause of bacterial enteritis. The increased use of selective media ${ }^{1}$ is an important factor in making these organisms the most frequently identified bacterial cause of diarrhoea. ${ }^{2}$ While the most common symptom is diarrhoea, coincident abdominal pain and the appearance of blood in the faeces may lead to hospital admission and sometimes even to laparotomy. In these circumstances culture of the faeces may be overlooked. We report our investigations into the serological response to C. jejuni/coli infection undertaken with the aim of evolving an additional, if retrospective, method of diagnosing these infections.

The antigenic structure of $C$. jejuni/coli is not known, but preliminary observations suggest that there are a number of different somatic and flagellar antigens. An effective diagnostic test should detect a range of these antigens, and accordingly we have investigated the antibody response to homologous and heterologous organisms. In the autumn and winter of $1978 / 79$ there were several milk-borne outbreaks of campylobacter infection. ${ }^{34}$ We have examined sera from patients in two of these outbreaks and observed the variability of the antibody response in a group of patients exposed to infection with a similar strain. In the outbreak of infection at Arnside, there appeared to be only one serotype involved, but in the much larger Luton outbreak there were at least two serotypes among the strains isolated from the patients.

Received for publication 7 January 1980

\section{Material and methods}

SERA

Convalescent sera collected from patients in the outbreaks at Luton and Arnside and from patients with sporadic campylobacter infections were examined. In general, these sera were collected 10 to 14 days after the onset of symptoms. For comparison, sera from antenatal patients were also examined. Rabbit sera used to control the techniques used in this study were raised by a course of intravenous injections of suspensions of either formolised or boiled organisms. 4

\section{AGGLUTINATION TESTS}

For presumptive ' $O$ ' agglutination, saline suspensions of organisms grown in the appropriate atmosphere 4 at $36^{\circ} \mathrm{C}$ for $18-24$ hours on blood agar plates (Oxoid CM271) were heated at $100^{\circ} \mathrm{C}$ for 15 minutes. Agglutination tests were done in $2 \times \frac{1}{2}$ inch tubes and read after incubation overnight at $50^{\circ} \mathrm{C}$. For presumptive ' $\mathrm{H}$ ' agglutination, suspensions were prepared in normal saline containing $0.3 \%$ formalin by a modification ${ }^{4}$ of the method of Watson et al. ${ }^{5}$ Tests were done in Dreyer's tubes and read after incubation for 4 hours at $37^{\circ} \mathrm{C}$.

\section{BACTERICIDAL TEST}

The bactericidal test was done in microtitre plates; $0.02 \mathrm{ml}$ volumes of inactivated serum were added to equal volumes of fresh guinea-pig complement and organism suspension and then incubated at $37^{\circ} \mathrm{C}$ for 30 minutes. One drop from each well was placed on 767 
dried blood agar plates and then incubated at $42^{\circ} \mathrm{C}$ overnight in the appropriate atmosphere. Diluent, complement, and positive serum controls were included. The presence or absence of growth was recorded.

\section{COMPLEMENT FIXATION TEST}

The antigen was prepared by sonication for 5 minutes of a thick suspension of organisms in distilled water. In preliminary experiments minor variations were observed using different antigens; for this study an antigen containing three serologically different strains was used and appeared to give a satisfactory spread of specificity. The test was performed by the Whitechapel technique in microtitre plates. ${ }^{6}$

\section{Results}

When tested against the appropriate homologous suspensions, the rabbit sera raised against formolised suspensions contained presumptive ' $\mathrm{H}$ ' and presumptive ' $O$ ' antibodies, and the sera raised against heated organisms contained only presumptive ' $O$ ' antibodies. ${ }^{4}$ The rabbit ' $\mathrm{OH}$ ' serum to the Arnside strain (type 3) was bactericidal at a dilution of $1 / 640$ and fixed complement at a 1/160 dilution. The rabbit serum to the Luton No. 1 strain (type 5) had a bactericidal titre of $1 / 10000$ and fixed complement at a $1 / 160$ dilution.

All 59 convalescent human sera failed to agglutinate the formolised suspensions, 50 sera agglutinated the boiled suspensions, and 55 sera showed complement-fixing activity. None of the convalescent sera had any bactericidal activity.

COMPLEMENT FIXATION TEST

Two hundred sera from antenatal patients were tested; $176(88 \%)$ of these were negative (less than $1 / 2), 20(10 \%)$ reacted weakly at a dilution of $1 / 2$, three reacted at $1 / 4$, and one reacted at $1 / 8$. All 20 convalescent sera from Arnside patients were positive at dilutions of $1 / 8$ to $1 / 128$. Twenty-two of 27 sera from Luton patients reacted similarly; the five Luton sera that were negative in the complement fixation test did not agglutinate heated organisms. All 12 convalescent sera from patients with sporadic infections were positive by the complement fixation test with titres ranging from $1 / 4$ to $1 / 128$.

AGgLUTINATION WITH HEATED ORGANISMS Eighty sera from antenatal patients were tested with suspensions made from the Arnside strain (type 3) and from one Luton strain (type 5); 10 agglutinated with both suspensions, and a further nine sera agglutinated with one suspension only, titres ranging from $1 / 20$ to $1 / 160$. For the examination of the convalescent sera suspensions were prepared from the Arnside strain and from two different strains isolated from Luton patients. The presence of at least one other serotype among the strains isolated from Luton patients became apparent during the typing of these strains. ${ }^{4}$ All 20 Arnside sera agglutinated the type 3 strain with titres in the range $1 / 160-1 / 2560$ but also agglutinated the Luton strains to lower titres (range 1/20-1/320). Nine of the 27 sera from Luton patients did not agglutinate with these suspensions. The remainder usually agglutinated one Luton strain to a higher titre than the other and also sometimes agglutinated the Arnside suspension. The converse was not seen with Arnside sera, which reacted poorly with the Luton strains. Sera collected from sporadic cases did not always agglutinate the Arnside or Luton suspensions although still showing complement fixing activity. Typical results are shown in Table 1.

Table 1 Complement fixation and $O$ agglutination titres of sera of selected patients from whom Campylobacter jejuni/coli was isolated

\begin{tabular}{lrrrr}
\hline Patient & CFT & \multicolumn{4}{c}{ Agglutinating strain } \\
\cline { 3 - 5 } & & Luton 1 & Luton 2 & Arnside \\
\hline A1 & $64^{*}$ & 320 & 320 & 2560 \\
A2 & 8 & 40 & 160 & 1280 \\
A3 & 8 & 40 & 40 & 1280 \\
A4 & 128 & 80 & 80 & 2560 \\
A5 & 64 & 160 & 320 & 2560 \\
L1 & 16 & 640 & 320 & 320 \\
L2 & 64 & 640 & 2560 & 2560 \\
L3 & 32 & 2560 & 2560 & 2560 \\
L4 & 8 & $<10$ & 40 & 640 \\
L5 & 32 & 640 & 80 & 80 \\
M1 & 8 & 320 & nt & 2560 \\
M2 & 8 & $<10$ & nt & $<10$ \\
M3 & 16 & 160 & nt & 40 \\
M4 & 32 & 320 & nt & 320 \\
M5 & 32 & 320 & nt & 640 \\
M6 & 4 & $<10$ & nt & 640 \\
\hline
\end{tabular}

A $=$ Arnside $; \mathbf{L}=$ Luton $\mathbf{M}=$ Manchester (sporadic) ; ${ }^{*}$ reciprocal dilution; $\mathrm{nt}=$ not tested.

DURATION OF ANTIBODY RESPONSE

Tests on sera collected serially from some patients indicated that the complement fixation antibody is usually detectable seven to $\mathbf{1 0}$ days after onset of symptoms and declines over a period of two months. The ' $O$ ' agglutinating antibody appears at the same time but probably remains detectable for much longer (Table 2).

\section{Discussion}

The serological response accompanying $C$. jejuni/coli infection has previously been investigated to a 
Table 2 Duration of antibody response

\begin{tabular}{lcrl}
\hline Patient & Days after onset & CFT & Agglutination \\
\hline 1 & 4 & $<2$ & $<10$ \\
& 11 & 16 & 320 \\
2 & 60 & 4 & 320 \\
& 5 & $<2$ & $<10$ \\
3 & 9 & 8 & 320 \\
& 24 & 64 & 640 \\
& 50 & 16 & 160 \\
\hline
\end{tabular}

limited extent by complement fixation, ${ }^{7}$ agglutination of formolised suspensions, ${ }^{5}$ and immunofluorescence. ${ }^{8}$ In this study we have sought to extend these observations. Although other workers ${ }^{5}$ have observed agglutination with formolised suspensions incubated overnight with convalescent sera, such agglutination may depend on somatic antigens in addition to flagellar antigens. We have observed that after overnight incubation formolised suspensions agglutinate with rabbit ' $O$ ' antisera. In this study, to minimise the ' $O$ ' agglutination element, incubation of ' $\mathrm{H}$ ' agglutinations was for 4 hours at $37^{\circ} \mathrm{C}$. Under these conditions ' $H$ ' agglutination was not observed in the patients' sera although it was demonstrable in rabbit antisera. The failure to demonstrate bactericidal activity in the convalescent sera also contrasts with the results obtained with rabbit sera and may be related to the intravenous route used for immunisation of the rabbits.

Agglutination with one or other of two heated suspensions was observed with $25 \%$ of antenatal sera although titres did not exceed $1 / 160$. In the convalescent sera, high agglutination titres were observed with the homologous organism but lower titres and sometimes negative reactions with heterologous strains. If the homologous strains were not available, then a number of different strains would need to be employed to obtain a satisfactory diagnostic titre. Even so, there would still be some chance of not having a strain with suitable antigens in the diagnostic suspensions. The agglutination titres last for many months, and this may lead to an additional difficulty in deciding whether a particular result indicates recent infection. Three sera from Luton patients reacted with the Arnside strain to a higher titre than with the Luton strains; four sera failed to agglutinate but were positive by complement fixation. These findings may indicate that two or more serotypes were responsible for the infections in Luton, and there is some evidence for this. ${ }^{4}$ Five sera from Luton patients were completely negative, and this may represent a lack of antibody response to gut infection in a minority of patients.

The complement fixation test was seldom positive in normal sera; only $0.5 \%$ reacted at a dilution of $1 / 8$. With the exception of five Luton patients, all convalescent sera examined have reacted in this test. The antigen prepared from three strains appears to be adequate, and possibly species-specific antigens are released by sonication. The use of homologous antigens prepared by sonication makes little difference to the titre obtained, and we have not observed any sera to be positive with an homologous antigen and negative with the antigen used in this study. The antibody appears to have waned after two months, and it would seem reasonable to take a complement fixation titre of $1 / 8$ or greater as indicative of recent infection. Where samples of serum were available early in the illness, neither agglutinating nor complement-fixing antibody was detectable three or four days after the onset of symptoms but the response was well developed by 10 days. Although the agglutination reaction is more sensitive it requires an homologous or related strain as the suspension. The use of a sonicate of a small number of different strains in a complement fixation test avoids this difficulty, and this test is sufficiently broad in its reactivity to be a useful diagnostic test where cultures have not been made.

We thank Dr L Robertson and Dr AT Willis for the patients' sera from Arnside and Luton.

\section{References}

${ }^{1}$ Skirrow MB. Campylobacter enteritis: a new disease. $\mathrm{Br}$ Med J 1977;2:9-11.

${ }^{2}$ Price AB, Jewkes J, Sanderson PJ. Acute diarrhoea: Campylobacter colitis and the role of rectal biopsy. J Clin Pathol 1979;32:990-7.

${ }^{3}$ Robinson DA, Edgar WM, Gibson GL, Matchett AA, Robertson L. Campylobacter enteritis associated with consumption of unpasteurised milk. Br Med J 1979; 1:1171.

${ }^{4}$ Abbott JD, Dale BAS, Eldridge J, Jones DM, Sutcliffe EM. Serotyping of Campylobacter jejuni/coli. J Clin Pathol 1980;33:762-6.

${ }^{5}$ Watson KC, Kerr EJC, McFadzean SM. Serology of human campylobacter infections. $J$ Infect $1979 ; 1: 151-8$.

- Price INO. Complement fixation technique. The Wassermann reaction. Br J Ven Dis 1950;26:172.

${ }^{7}$ Butzler JP. Related vibrios in Africa. Lancet 1973;2:858 (correspondence).

${ }^{8}$ Blaser M, Cravens J, Powers BW, Wang WL. Campylobacter enteritis associated with canine infection. Lancet $1978 ; 2: 979-81$.

Requests for reprints to: Dr DM Jones, Public Health Laboratory, Withington Hospital, Manchester M20 8LR, UK. 